\title{
STATUS TEKANAN DARAH MAHASISWA DENGAN RIWAYAT NON COMMUNICABLE DISEASE PADA ORANGTUA
}

\author{
Rahmi Susanti ${ }^{1}$, Eka Nur Annisa Rahmayanti ${ }^{2}$, Najla Sari ${ }^{3}$ \\ ${ }^{1,2,3}$ Bagian Biostatistika dan Ilmu Kependudukan FKM Universitas Mulawarman
}

\begin{abstract}
ABSTRAK
Non Communicablediseases atau penyakit tidak menular sebanyak $70 \%$ bertanggungjawab atas kematian didunia, yang mayoritas terjadi di negara dengan pendapatan menengah dan rendah. Penelitian ini bertujuan untuk mengetahui pengaruh status riwayat kesehatan orangtua (hipertensi, hiperkolesterolmia dan diabetes melitus) pada tekanan darah mahasiswa. Penelitian ini menggunakan desain survei analitik dengan metode cross sectional. Sampel diperoleh sebanyak 31 mahasiswa Fakultas Kesehatan Masyarakat, Universitas Mulawarman dengan teknik purposive sampling. Analisis statistik menggunakan Uji Kruskal Wallis dengan tingkat kesalahan 5\%. Riwayat penyakit orang tua dari responden antara lain hipertensi sebesar 48,15\%; hiperkolesterolmia sebesar 37,04\%; dan diabetes melitus sebesar 14,81\%. Responden dalam penelitian ini dibagi menjadi 3 kelompok yaitu responden dengan kedua orang tua memiliki riwayat penyakit, salah satu orang tua memiliki riwayat penyakit dan kedua orang tua tanpa riwayat penyakit. Hasil uji bivariat menunjukkan P Value 0,323 yang bermakna tidak terdapat perbedaan yang signifikan antar ketiga kelompok responden. Hasil penelitian menunjukkan bahwa tidak ditemukan pengaruh status riwayat penyakit orangtua dengan tekanan darah remaja
\end{abstract}

Kata Kunci : Hipertensi, Diabetes Melitus, Hiperkolesterolmia

\section{PENDAHULUAN}

Penyakit tidak menular, termasuk penyakit kardiovaskular, kanker, diabetes dan penyakit pernapasan kronik serta faktor risiko seperti rokok, minuman beralkohol, diet yang tidak sehat dan kurangnya aktifitas fisik menjadi penyebab utama kematian didunia.

Non Communicablediseases atau penyakit tidak menular sebanyak $70 \%$ bertanggungjawab atas kematian didunia, yang mayoritas terjadi di negara dengan pendapatan menengah dan rendah (WHO, 2016).

Di Indonesia, penyakit tidak menular menjadi penyebab kematian terbanyak. Hal ini menjadi beban ganda dalam pelayanan kesehatan.Proporsi angka kematian akibat penyakit tidak menularmeningkat dari 41,7\% pada tahun 1995 menjadi 49,9\% pada tahun 2001 dan 59,5\% pada tahun 2007. Penyebab kematian tertinggi dari seluruh penyebab kematian adalah stroke 
$(15,4 \%)$, disusul hipertensi, diabetes, kanker, dan penyakit paru obstruktif kronis.

Kematian akibat penyakit tidak menular terjadi di perkotaan dan perdesaan. Data Riskesdas 2007 menunjukkan di perkotaan, kematian akibat stroke pada kelompok usia 45-54 tahun sebesar 15,9\%, sedangkan di setiap hari, 93,6\% kurang konsumsi buah dan sayur serta 48,2\% kurang aktivitas fisik (Kementerian Kesehatan Republik Indonesia, 2011)

Trend global menunjukkan bahwa hubungan perilaku dengan Non Communicablediseases pada kaum muda yakni 3 dari 4 remaja yang mengalami obesitas akan

Tabel 1. Distribusi Frekuensi Karakteristik Responden

\begin{tabular}{lll}
\hline Variabel & $\mathrm{f}$ & $\%$ \\
\hline Jenis Kelamin & & \\
Laki-laki & 7 & 22,58 \\
Perempuan & 24 & 77,42 \\
Umur & & \\
19-20 tahun & 9 & 29,03 \\
21-22 tahun & 22 & 70,97 \\
Riwayat penyakitorangtua & & \\
Hipertensi & 13 & 48,15 \\
Diabetes Melitus & 4 & 14,81 \\
Hiperkolesterolmia & 10 & 37,04 \\
\hline
\end{tabular}

Sumber: Data Primer dan Sekunder, 2018

perdesaan sebesar 11,5\%. Hal tersebut menunjukkan penyakit tidak menular (utamanya stroke) menyerang usia produktif. Sementara itu prevalensi penyakit tidak menularlainnya cukup tinggi, yaitu: hipertensi $(31,7 \%)$, arthritis $(30.3 \%)$, penyakit jantung $(7.2 \%)$, dan cedera $(7,5 \%)$. penyakit tidak menulardipicu berbagai faktor risiko antara lain merokok, diet yang tidak sehat, kurang aktivitas fisik, dan gaya hidup tidak sehat. Riskesdas 2007 melaporkan, 34,7\% penduduk usia 15 tahun ke atas merokok meningkatkan risiko penyakit hati, diabetes tipe 2, stroke dan kanker, Antara $20-40 \%$ remaja yang mengalami kelebihan berat badan (overweight) dibandingkan dengan yang tidak akan 2 kali lebih berisiko mengalami penyakit kardiovaskular dan 7 kali memiliki risiko untuk terkena aterosklorosis, 25\% remaja yang mengalami obesitas menunjukkan gejala diabetes, dan prevalensi penderita hipertensi pada remaja adalah sebesar 4,5\% (John Hopkins School of Public Health). 
Masalah kesehatan usia remaja merupakan salah satu masalah penting dalam siklus kehidupan. Masalah kesehatan di usia dewasa sebagian berkaitan dengan perilaku kesehatan ataupun gaya hidup di usia muda termasuk di usia remaja. Perilaku hidup sehat sejak usia dini merupakan salah satu upaya yang cukup penting dalam menciptakan sumber daya manusia yang produktif dan berkualitas di masa yang akan datang (Balitbangkes RI, 2015)

Hasil RISKESDAS tahun 2013 Provinsi Kalimantan Timur memberikan informasi prevalensi penyakit menular yakni 2,3\% diabetes, $29,6 \%$ hipertensi, $1 \%$ jantung koroner dan 1,2\% stroke. Prevalensi diabetes tertinggi di samarinda yakni $4,1 \%$, prevalensi hipertensi sebesar 30,8\%, dan terjadi pada usia $>15$ tahun untuk penyakit diabetes dan usia $>18$ tahun untuk hipertensi (Riskesdas, 2013).

\section{METODE PENELITIAN}

Penelitian ini menggunakan desain survei analitik dengan metode cross sectional. Variabel-variabel dalam penelitian hanya diukur pada saat itu, kemudian mencari hubungan antar variabel satu dengan variabel lainnya.

Pengambilan data dilakukan pada April 2018.Seluruh mahasiswa/i Fakultas Kesehatan Masyarakat, Universitas Mulawarman, Samarinda, Kalimantan Timur menjadi populasi dalam penelitian ini.Teknik pengambilan sampel yang digunakan pursposive sampling.

Sampel diperoleh sebanyak 31 mahasiswa dengan kategori kedua orang tua memiliki riwayat penyakit, salah satu orang tua memiliki riwayat penyakit dan kedua orang tua tanpa riwayat penyakit. Pengambilan data dilakukan dengan pengukuran untuk memperoleh tekanan darah sistol dan wawancara untuk memperoleh riwayat penyakit orang tua. Pengolahan dan analisis data menggunakan analisis univariat dan analisis bivariat (Uji Kruskal Wallis dengan $\alpha=0,05)$.

\section{HASIL PENELITIAN}

Hasil penelitian pada tabel 1 menunjukkan bahwa data distribusi karakteristik responden berjenis kelamin laki-laki sebesar 22,58\%, sedangkan responden berjenis kelamin perempuan sebesar 77,42\%. Responden yang berusia 19-20 tahun sebesar $29,03 \%$ sedangkan responden yang berusia 21-22 tahun sebesar 70,97\%. Adapun riwayat penyakit orang tua dari responden antara lain hipertensi sebesar 48,15\%; hiperkolesterolmia sebesar 37,04\%; dan diabetes melitus sebesar $14,81 \%$.

Pada table 2 menunjukkan informasi bahwa rerata tekanan darah pada responden dengan kedua orangtua tanpa riwayat penyakit lebih besar daripada kedua kelompok 
lainnya yakni 117,67 dengan tekanan darah tertinggi yang diperoleh adalah 132 .

Pada tabel 3 memaparkan bahwa terdapat tiga kelompok yang dibandingkan yakni responden dengan kedua orangtua menderita/ memiliki riwayat penyakit tidak menular, salah satu dari orangtua baik ibu
rah.Tekanan darah ini dipengaruhi oleh volume darah dan elastisitas pembuluh darah.Peningkatan tekanan darah disebabkan peningkatan volume darah atau elastisitas pembuluh darah. Sebaliknya, penurunan volume darah akan menurunkan tekanan darah.

Tabel 2. Ukuran Pemusatan Tekanan Darah Responden berdasarkan status riwayat Non Communicable Disease pada Orangtua

\begin{tabular}{clccc}
\hline No & \multicolumn{1}{c}{ Kelompok } & Mean & Min & Max \\
\hline 1 & $\begin{array}{l}\text { Kedua orangtua dengan riwayat pen- } \\
\text { yakit }\end{array}$ & 114,40 & 107 & 129 \\
2 & $\begin{array}{l}\text { Salah satu orangtua memiliki riwayat } \\
\text { penyakit }\end{array}$ & 111,50 & 92 & 129 \\
3 & $\begin{array}{l}\text { Kedua orangtua tanpa riwayat pen- } \\
\text { yakit }\end{array}$ & 117,67 & 101 & 132 \\
\hline
\end{tabular}

Sumber: Data Primer, 2018

atau bapak yang memiliki riwayat penyakit tidak menular dan kelompok yang memiliki kedua orangtua tanpa riwayat penyakit tidak menular. Hasil uji statistika menunjukkan nilai $p$ value yang besar yakni 0,323 yang membuktikan bahwa tidak ada perbedaan tekanan darah remaja berdasarkan riwayat penyakit tidak menular pada orangtua mereka.

\section{PEMBAHASAN}

Tekanan darah adalah tekanan yang dihasilkan oleh darah terhadap pembuluh da-
Tekanan darah digolongkan menjadi dua macam, yaitu tekanan darah sistol dan tekanan darah diastol.Tekanan darah sistolmerupakan tekanan darah yang tercipta karena adanya kontraksi jantung sehingga mendorong darah melalui arteri ke seluruh tubuh manusia.Pengukuran tekanan darah sistol mengacu pada jumlah tekanan darah yang ada dalam arteri. Rata-rata tekanan darah sistol dari keseluruhan responden dalam penelitian ini ialah 114,2 mmHg. Jika merujuk pada kriteria yang telah dibuat JNC VII 2007 yang menyatakan bahwa bila 
salah satu dari sistol maupun diastol melebihi batas normal yang telah di tetapkan maka dikategorikan hipertensi.Sejalan dengan bertambahnya usia, hampir setiap orang mengalami kenaikan tekanan darah, tekanan darah sistol terus meningkat sampai usia 80 tahun, sementara tekanan darah
(NHNES III) mencatat, bahwa Insiden hipertensi di Amerika tahun 2010-2012 adalah sekitar 39-51\%.

Hasil penelitian menunjukkan tidak adanya perbedaan tekanan darah responden yang berasal dari kelompok orangtua dengan status riwayat penyakit yang ber-

Tabel 3. Hasil Bivariat Perbandingan Tekanan Darah Responden berdasarkan status riwayat Non Communicable Disease pada Orangtua

\begin{tabular}{ccccc}
\hline No & Kelompok & $\mathrm{n}$ & $\begin{array}{c}\text { Nilai Hitung Kruskal } \\
\text { Wallis }\end{array}$ & P Value \\
\hline 1 & $\begin{array}{c}\text { Kedua orangtua dengan ri- } \\
\text { wayat penyakit }\end{array}$ & 10 & & \\
2 & $\begin{array}{c}\text { Salah satu orangtua } \\
\text { memiliki riwayat penyakit }\end{array}$ & 12 & 2,258 & 0,323 \\
3 & $\begin{array}{c}\text { Kedua orangtua tanpa ri- } \\
\text { wayat penyakit }\end{array}$ & 9 & & \\
\hline
\end{tabular}

Sumber: Data Primer, 2018

diastol terus meningkat sampai usia 55-60 tahun, kemudian berkurang secara perlahan, atau bahkan menurun drastis.

Salah satu faktor risiko penyakit tidak menular adalah peningkatan tekanan darah, yang dapat berhubungan dengan meningkatnya angka kesakitan dan angka kematian yang disebabkan penyakit kardiovaskuler. Berdasarkan data statistik WHO (2012) peningkatan tekanan darah menyebabkan 51\% kematian penderita stroke dan $48 \%$ kematian penderita penyakit pembuluh darah jantung (WHO, 2012). National Health and Nutrition Examinations Survey
beda.Hasil tersebut ditunjukkan pula oleh penelitian Kalangi dkk (2015) dimana diperoleh hasil bahwa dari 80 siswa tidak ditemukan hubungan faktor genetik orangtua dengan tekanan darah remaja.Walaupun pada penelitian yang Frankilwati (2014) kejadian diabetes mellitus tipe II dipengaruhi oleh genetik.Penelitian Frankilwati tidak sesuai dengan penelitian yang dilakukan oleh Santosa (2017) yang membuktikan bahwa salah satu penyakit tidak menular yakni diabetes melitus tidak diturunkan dari garis keturunan orangtua yang memiliki riwayat penyakit diabetes meli- 
tus.Faktor penyebab penyakit tidak menular seringkali susah untuk diidentifikasi karena begitu banyak faktor yang berperan. Dalam teori yang dipublikasikan oleh WHO (2012), genetik merupakan salah satu faktor risiko umum terjadinya non communicable disease.Namun, dalam kerangka teori tersebut ditunjukkan bahwa terdapat faktor perantara antara genetik dengan kejadian penyakit tidak menular yakni seperti gula darah tinggi, tekanan darah tinggi, lemak darah abnormal, obesitas dan lainnya.

Penyakit tidak menular seperti hipertensi maupun diabetes selain disebabkan oleh faktor genetik, juga dipengaruhi oleh umur, jenis kelamin, dan ras. Ada sekitar duapuluh sampai limapuluh gen yang mengatur tekanan darah. Stress dan faktor lingkungan juga dapat menyebabkan hipertensi, tetapi hipertensi yang disebabkan faktor genetik lebih memerlukan perhatian yang khusus (Lewis, 1999).

Umur mempunyai peranan penting sebagai penyebab hipertensi.Atheroclerosis atau arteriosclerosis adalah akumulasi masa lemak pada bagian dalam pembuluh darah yang biasanya sudah dimulai sejak umur dewasa sampai paruh umur tanpa menimbulkan gejala.Atheroclerosis cenderung terdapat pada orang dengan hipertensi. Pada beberapa keluarga atherochlorosis merupakan kondisi yang diturunkan,seperti halnya hypercholesterolemia (Mader, 1998)
Walapun Fakta pada penelitian Henuhili dkk (2011) menunjukkan bahwa faktor keturunan lebih banyak memegang peranan timbulnya penyakit hipertensi dibandingkan faktor lingkungan tetapi pada penelitian ini hal tersebut belum dapat dibuktikan.

Ketiadaan perbedaan tekanan darah pada penelitian ini dapat menjadi pengamatan lebih lanjut, karena hal tersebut bisa diakibatkan oleh ketidakcukupan besar responden yang digunakan sebagai sampel penelitian.

\section{KESIMPULAN}

Tiga kelompok responden dengan status riwayat penyakit orangtua yang berbeda menunjukkan tidak adanya perbedaan tekanan darah yang mereka miliki saat diukur $(\mathrm{p}$ value $>\mathrm{a})$. Tekanan darah tertinggi yang terukur dari 31 responden adalah 132.

\section{SARAN}

Penelitian ini dilakukan untuk mendeteksi gejala dini penyakit tidak menular pada usia remaja hingga dewasa muda, walaupun hasil tidak menunjukkan perbedaan yang signifikan, remaja dan dewasa muda diharapkan untuk dapat memantau kesehatan secara rutin, melakukan perilaku hidup sehat, dan menjauhi risiko terjadinya penyakit tidak menular atau Non Communicable Disease (NCDs) 


\section{DAFTAR PUSTAKA}

Frankilwati \& Dyah, A.M 2013,Hubungan antara pola makan, genetik dan kebiasaan olahraga terhadap kejadian diabetes melitus tipe II di wilayah kerja puskesmas nusukan surakarta. Skripksi tidak dipublikasikan.

Henuhili dkk,2011,Pola Pewarisan Penyakit Hipertenis dalam Keluarga sebagai Sumber Belajar Genetika. Prosiding Seminar Nasional Penelitian, Pendidikan dan Pengabdian MIPA UNY. 2011:B242-7

Santosa, Trijayanto, \&Endiyono, 2017,Hubungan Riwayat Garis Keturunan dnegan usia terdiagnosis Diabetes Melitus tipe II. Universitas Muhammadiyah Magelang

Mader, S 1998,Human Biology. $5^{\text {th }}$ ed, McGraw-Hill, Boston

Lewis, R 1999,Human Genetics, Concept and Aplicatioans. $3^{\text {rd }}$ ed, McGraw-Hill, Boston

John Hopkins School of Public Health. NonCommunicable Diseases and Adolescent.Young Health Programme. Tersedia dari : https:// www.jhsph.edu/research/centers-and -institutes/center-foradolescent- health/_includes/_preredesign/az/ noncommunicable.pdf

Kalangi J, Umboh A, \& Pateda, V 2015, Hubungan faktor genetik dengan tekanan darah pada remaja, Jurnal eclinic (eCI), Vol. 3, no. 1 Januari - April 2015

Kementerian Kesehatan Republik Indonesia, 2011,Penyakit Tidak Menular (PTM) Penyebab Kematian Terbanyak di Indonesia. Sitasi 15 September 2017. Tersedia dari : http:// http://www.depkes.go.id/article/print/16 $\underline{37}$

WHO, 2012, The global status of NCDs, Sitasi 05 Maret 2018.Tersedia dari : http://www.who.int/chp/ncd global status report/en/

World Health Organization, 2016,Assesing National Capacity For The Prevention And Control Of Noncommunicable Diseases: Report of the 2015 Global Survey, WHO Library Cataloguing-inPublication Data, Geneva

RISKESDAS, 2013,Pokok-Pokok Hasil Riset Kesehatan Dasar Provinsi Kalimantan Timur, Badan Penelitian dan Pengembangan Kesehatan Kementerian Kesehatan RI Tahun 2013, Tersedia dari :http://biofarmaka.ipb.ac.id/biofarmaka/20 14/Riskesdas2007 